\title{
Supply chain management and logistic presentation: Mediation effect of competitive advantage
}

\author{
Kannapat Kankaew $^{\mathrm{a}}$, Lis M Yapanto ${ }^{b^{*}}$, Rojanard Waramontri ${ }^{\mathrm{c}}$, Sjamsul Arief ${ }^{\mathrm{d}}$, Hamsir ${ }^{\mathrm{e}}$, Nila \\ Sastrawati ${ }^{\mathrm{f}}$ and Marcos Rosamel Espinoza-Maguiña ${ }^{\mathrm{g}}$
}

\author{
${ }^{a}$ College of Hospitality Industry Management, Suan Sunandha Rajabhat University, Thailand \\ ${ }^{b}$ Faculty of fishery and Marine Science, Universitas Negeri Gorontalo, Indonesia \\ ${ }^{c}$ Airline Business, Suan Sunandha Rajabhat University College of Hospitality Industry Management Thailand \\ ${ }^{d}$ Institution, organization, educational institution, Economics and Business Faculty: Universitas Tujuh Belas Agustus 1945 Surabaya, Indonesia \\ ${ }^{e}$ Professor Assisstant, Dr. ; S.H ; M.Hum (Dr. Hamsir, SH., M.Hum), UIN Alauddin Makassar, Indonesia \\ ${ }^{f}$ Professor Assistant, Faculty of Sharia and Law, UIN Alauddin Makassar, Indonesia \\ ${ }^{g}$ Universidad Nacional Santiago Antúnez de Mayolo, Perú
}

\section{H R O N I C L E}

Article history:

Received November 8, 2020

Received in revised format

January, 28, 2021

Accepted March 242021

Available online

March 252021

Keywords:

Competitive advantage

Logistic performance

Supply chain management

PLS-SEM

\section{A B S T R A C T}

\begin{abstract}
Supply chain management (SCM) practices have become strategic resources and capabilities for enhancing both competitive advantage logistic performance (ORGPER). However, it is not clear how SC Practices influence logistic performance in the agribusiness context. However, the mechanism of SCMPs effects is not yet understood since extant literature has produced mixed results. Hence, this study sought to test the impact of mediation of the competitive advantage of relations between SCMP and Reperform the point of view of Kenya's dairy supply chain. The study examined four estimates that were tested using partial minimum square structural equation modeling (PLS-SAME) techniques to work out the purpose of the study. Across-departmental survey design has been used to collect preliminary data from 109 dairy cooperatives in thirteen major dairy producing counties in Kenya. The results reveal that SCM practice has a positive and significant effect on $\mathrm{CA}(\mathrm{P}=0.730)$ and ORGPER $(\mathrm{P}=0.237)$. In addition, THERE is a positive, statistically significant effect on THECAORGPER $(\mathrm{P}=0.522)$. Further results show that CA mediates the relationship between SCMP and ORGPER. Consequently, the study concludes that SCMPs first generate CA, which in turn enhances ORGPER in a logistic sense. Theoretically, the study provides insights on the resource-based view theory as well as a conceptual framework for its validation. Similarly, the study informs managers and policymakers in knowing specific SCMPs to focus on to enhance CA and ORGPER of the dairy cooperatives in Kenya.
\end{abstract}

(C) 2021 by the authors; license Growing Science, Canada.

\section{Introduction}

Agricultural supply chains (ASC) play a critical role in providing access to markets (local, regional and international) for the farming communities. However, changes in the current marketplace limit the ability of agricultural enterprises to compete (Abbey et al., 2013). Currently, the market has become highly globalized, with high quality, price addition and rapid demand for customized agricultural food products (Ali et al., 2018). Thus, small and large agribusiness firms alike have to innovate to achieve cost efficiencies while still attempting to be flexible and responsive to the dynamic customer demand in the marketplaces (Anatan, 2014; Martínez-Navalón et al., 2019). Modern management thinking is advocating for the coordination, activation and management of important business processes across members of the supply chain as a new way to survive global competition and achieve sustainable performance (Apopa, 2018). Against this backdrop, supply chain management SCM has become part of business management approach that provides a framework for integrating an

* Corresponding author

E-mail address: lizrossler@ung.ac.id (L. M. Yapanto)

(C) 2021 by the authors; licensee Growing Science. doi: $10.5267 /$ j.uscm.2021.3.007 
elaborate network of business relationships from material suppliers to ultimate customers (Arham, 2014). SCM should manage the relationship between the companies responsible for efficient production and supply of consumers from the agricultural level, meeting the requirements of consumers in terms of quantity, quality and prices reliable (Babatunde, Gbadeyan \& Bamiduro, 2015). Effective SCM has become a valuable source of improving CA and The ORGPER since competition is no longer within the company but within the supply chain (Banerjee \& Mishra, 2017). In the long run, SCMP application swells market share and increases profits for all members of the supply chain (Barasa, 2017). Despite the continued focus on research on SCM, the methodology of SCMP's impact on the organper is not yet clear. According to Carrión et al. (2017), the nature of the connection between SCMPs and ORGPER can be direct or indirect, serial or nonserial, interdependent or opposite. However, most past studies often do not consider the impact of mediation in their estimates, contributing to SCMP combined research and performance incomplete (Carrion et al., 2017 ). As a result, this narrow focus leads to biased explanations of results for a variable that may not have direct effects but instead has an effect through another variable (Chege, 2017). Recent research is trying to experience this knowledge gap by using Kenya's dairy supply chain to investigate the impact of mediation between SCMP and institutional performance. This result will not only provide additional insight into the effectiveness of SCM practice from a research point of view but will also provide relevant effects to practicing managers who are more interested in learning specific SCM practices responsible for improving performance in the dairy industry.

\section{Literature review}

\subsection{Supply Chain Management Practices (SCMPs)}

SCM practice is seen from different perspectives and from multidimensional concepts (Diaconu \& Alpopi, 2014). As a result, literature is full of SCMP levels from different perspectives but lacks consensus on relevant construction (Anatan, 2014; Odendaal, 1981). Strategic supplier partnerships, customer relations, data sharing levels, data sharing standards, and SCMPS levels are used as suspended. Another research (Dikshit \& Trivedi, 2012a) highlights collaboration, demand and supply plan, list production and distribution management and logistics are used as SCMP (Tatoglu, etal., 2016; Tsolakis, et al., 2014; Maina, Njehia \& Eric, 2020). In addition, four dimensions of SSC practice, such as green supply chain, customer relationship management (Barasa, 2017), supplier relationship management, outsourcing practice and in supply chain. In addition, Dikshit \& Trivedi's (2012b) ideas are supply chain cooperation practices, Green practice, data practice, customer practice. In the same breath, Dries et al. (2014) present providers use range practices, supply chain policies, supplier assistance practices, risk management practices. In addition, Carrion, Nitzl \& Roldan (2017) are of the view that benefactor relationship management practices, procedure management practices, client relationship management practices and IT care practices are cast-off (Wijetunge, 2016; Wong, 2019; Wong \& Wong, 2011). Existing SCMP generally requires more specific practices in the management of the dairy supply chain (Fornell \& Larcker, 1981). Therefore, the following procedures have been identified about the dairy supply chain; Information and Communication Technology Practices (Franke \& Sarstedt, 2019), Supplier Relationship Practices, Supply Chain Manufacturing Practices, List Management Systems, Warehousing Management Systems, Transportation Management Systems, Customer Relationship Management. In this way, the current study proposes Customer Relationship Management (CRM), Information and Communication Technology (ICT), Logistics Management (LM), Management (PM) and Supplier Development (SD). The five SCMP supply chain has internal practices across both sides and the focus for the company (Hair, Howard \& Nitzl, 2020).

\subsection{Logistic Performance}

ORGPER means a company achieving both market-oriented and financial goals (Garson, 2016; Prajapati, Kant \& Gorane, 2018). According to the High Performance Firms, Big companies and societies like wealth attraction, wealth generation and employment generation can produce various benefits. Consequently, literature has identified various stages of institutional achievement, such as working, financial and market performance. Parameters, demand management, customer satisfaction and shareholder satisfaction as ORGP measurements. Other measures include activation, inflexibility and quality (Hair, Hult \& Christian, 2017). Another study has been carried out to visualize effective customer satisfaction and institutional performance in terms of financial standards. In short, ORGPER can be classified as a financial or non-financial metric. In the light of this present literature, current research is effective as anORGPER measurement, market and customer satisfaction proposal.

\subsection{Competitive advantage}

CA refers to the level where a company can build a safe position on its rivals. It consists of qualifications that allow a company to separate itself from its rivals and a result of complex management decisions. Previous research suggests that different dimensions affect skimps" price, quality, supply, product innovation, and the competitive advantage of supply chain through time in the market" For example, Anatan (2014) has ensured that SCM practice affects CA through price, quality, delivery, product innovation and market time. Dikshit \& Trivedi (2012b) are of the view that the price as a level of competitive advantage, premium price, price-to-customer value, reliable supply, and product innovation are considered. In this way, the current study included quality, supply reliability, and inflexibleness as a measure of competitive advantage. 
SCMP not only improves the financial metric but also increases market performance and customer satisfaction. Efficient SCMPs have reduced list levels, empty warehouse space, cash flow and improved customer relations potential. In addition, SCMPs can increase the inability by improved control of supply, thereby increasing capacity usage (Dikshit \& Trivedi, 2012a). Based on the above, this study posts that:

$\mathbf{H}_{1}$ : SCM practices have significant effects on logistic performance.

$\mathbf{H}_{2}$ : SCM practices have significant effects on competitive advantage.

SCMP can enable a company to separate from its rivals in relations of price/worth, quality, supply reliability and time in market. In addition, the market is led by efficient use of an efficient SC resource, which provides a competitive advantage of low product, improved product quality, rapid response, and finally. This capacity can not only improve the performance of the competitive advantage and not only the overall company but also improve the overall supply chain performance (Dikshit \& Trivedi, 2012b). For example, SCMP delivery helps reduce lead-time and increase reactiveness, thereby creating a competitive advantage for the firm. Therefore, this study suggests that:

$\mathbf{H}_{3}$ : CA has a significant effect on logistic performance.

$\mathbf{H}_{4}$ : Competitive advantage mediates the relationship between SCMPs and logistic performance.

\subsection{Conceptual framework}

The hypothetical framework developed in this study proposes SCMP direct and indirect impact on the logistics of dairy cooperation in Indonesia (Hair, et al. 2019). Therefore, SCMP is expected to generate competitive advantage to the first generation, in turn improving logistics performance. Previously, various SCM methods affected many aspects of operational performance. Fig. 1 below represents the proposed conceptual for this study.

\begin{tabular}{|c|c|c|}
\hline Supply chain management practices & Competitive advantage & Logistics performance \\
\hline Procurement Management (PM) & Quality & Market Performance \\
\hline Logistics Management (LM) & Delivery Dependability & Operational Performance \\
\hline $\begin{array}{l}\text { Customer Relation Management (PM) } \\
\text { Supplier Management (SM) }\end{array}$ & Flexibility & Customent Satisfaction \\
\hline
\end{tabular}

\section{Method}

Fig. 1. Conceptual Frame work

\subsection{Measures of variables}

Multiple item scales have been created to measure the levels of SCMPs, such as Info and communication technology, supplier progress, purchase, logistics, and customer relations management. In addition, the scale of multiple items is taken from past research to measure the level of construction (quality, supply reliability, and inflexibleness). In addition, multiple item scales are taken from past research to measure Logistic performance levels (market, operational and customer satisfaction). Scale item for SCM exercise 7 points The Likert scale is measured from 1 to 7 for each time. Similarly, a seven-Likert scale $1=$ strongly disagreed $7=$ strongly agreed market performance, functional performance and customer satisfaction are accepted to measure Logistic performance.

\subsection{Data}

The study's population consists of dairy cooperatives operated in thirteen major dairy producing counties in Indonesia. A sample of 109 dairy cooperatives was selected from a population of 150 people, where the unit manager represented each of them as survey respondents. A cross-sensitive survey design is used to collect basic information using cross finished q; And after this field survey, a total of 100 questionnaires were returned, representing a response rate of about $92 \%$. However, out of the 100 question papers returned, only 89 are complete and valid for analysis.

\subsection{Data analysis}

The current research experience applies structural equation modeling (SEM) methods to conduct analysis. SEM is a multifaceted analytical tool that has become common in complex interrelationship analysis (Sarstedt, Hopkins \& Kuppelwieser, 2014) between tested and lazy variables. There are two types of SAME, such as factor/diversity-based CVSAME and component/diversity based VB-SAME. However, when both methods are presented by clusters of tested variables, multiple independent and dependent variables are together: they are conceptually different in the construction measurement and model estimate method (Henseler, et al. 2014). treatment. While THE CV-SAME reduces the difference 
between a tested diversity matrix and an indication covariance matrix, THE VB-SAME increases the amount of explained variation in dependent endogenous formation (Lorentz, et al., 2011; Sundram, Ibrahim \& Govindaraju, 2011; Tailab, 2020) According to Henseler, Ringle \& Sarstedt (2015), the VB-SEM involves various techniques, such as a regression on sum score or retreat on the main component, generalised structured component analysis (GSCA) and partial minimum square road modelling (PLS) (Henseler, Ringle \& Sarstedt, 2015). PLS-SEM path modelling is suitable for estimating many theoretical models and the model because of the empirical data situations, so is considered a "silver bullet" (Henseler \& Sarstedt, 2013). A benefit of PLS-SEM on other VB-SEM methods is the skill to mention the composite interrelationship among the observed and latent variables (Hwang, Sarstedt, Cheah \& Ringle, 2020). Furthermore, PLS-SAME is a factor prediction method of SEM that insists on statistical model estimates, while providing causal explanations. The interaction among interpretation and predictor theory provides a description of the causal causes and predictions, in addition to theoretical structures and relationships between them (Johnson \& Hofman, 2004). Based on this, current research sets the PLS-SAME strategy to settle as the most suitable statistical method for objective analysis. The application of PLS-SAME has been expanded in various academic branches. Such as international business marketing, human resource, accounting, strategic, tourism, hospitality and agricultural science and management (Hair, Sarstedt, Ringle \& Gudergan, 2017). For example, Sundram, Ibrahim, \& Govindaraju (2011), applied PLS-SAME to investigate the impact of SCMP on the presentation of the supply chain in electronics business.

\subsection{PLS-SEM}

The research, according to Johnson \& Hofman (2004), suggested by taking a two-step approach, first assessing the measurement model, evaluating the structural model using SmartPLS 3.2.9 software. SmartPLS is a user-friendly software that usually requires little technical knowledge about the method.

\section{Results}

\subsection{Model}

There are two ways to introduce external models; Reflective or constructive (formative). Indicators or manifest variables are created by a reflector measurement model (Garson, 2016). influenced, or by the underlying talent variable. Conversely, a structural lazy construction index is caused instead of caused by built-in lant (Koh, et al. 2007). By means of the SmartPLS Confirmed Tetrod Analysis (CTA) algorithm, current research has confirmed that SCMPs, CA and ORGPER reflect measurement models, as shown in Fig. 3. Previous studies have shown similar results; Therefore, this study has concluded that SCMPs are models reflected in CA and ORGPER.

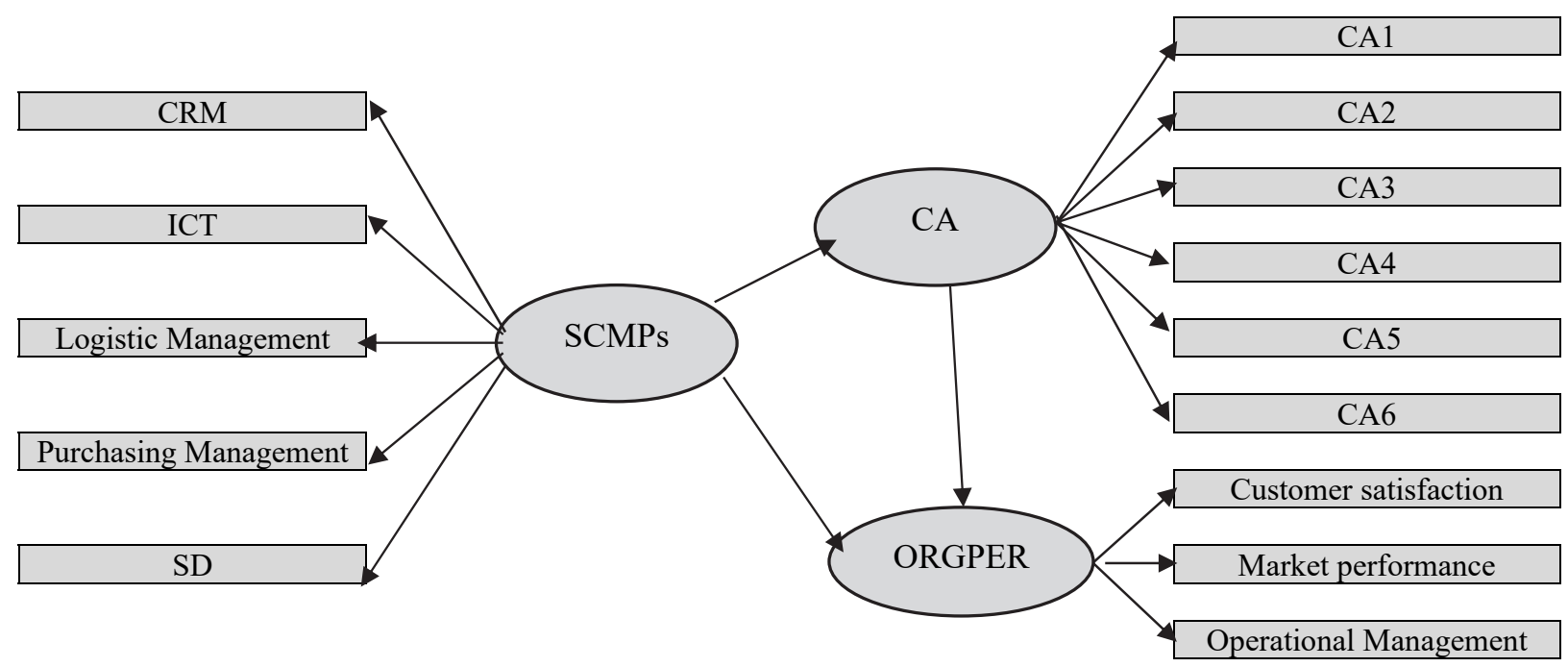

Fig. 2. Measurement Model

\subsection{Evaluation of Measurement Model}

According to assessing a reflective measurement model requires establishing indicator dependability, internal consistency dependability, hypothesis validity, convergent and discriminant validity (Kumar, 2020). Evaluation of the measurement model of reflection measurement assesses reliability of measurement (i.e., directive dependability and inner continuity dependability), and tenure (i.e., coordinated and discriminatory tenure) (Ali, et al. 2018).

Indicator Reliability

Indicator loading and their importance are determined by observing the reliability of the index. According to Hair, et al. (2020), standard loading value should be important for two-foot tests with a respective T-statistic above 0.708 and above \pm 1.96 . In addition, biased biased-corrected and accelerated ( $(\mathrm{BCa})$ confidence breaks are observed that index loading has 
not included zero to be statistically significant. Therefore, a bootstrapping process is implemented with 5,000 subsamples and 5\% two-tail test testing at the importance level. Table 1 displays that all the standardised indicator loadings for the three concepts are overhead the smallest limit of 0.708 but CRM (0.663) That is, the latent variables More than captured $50 \%$ of respectively of his indicators. In addition, t statistics of all indicators loading sits at $1.96>$ for three constructions, and their confidence break value is not included zero, thereby displaying a suitable level of indicator reliability.

Table 1

Test of Significance for the Outer loading

\begin{tabular}{|c|c|c|c|c|c|c|}
\hline \multirow[t]{2}{*}{ Indicator } & \multirow{2}{*}{$\begin{array}{c}\text { Original Sample } \\
\text { (O) }\end{array}$} & \multirow{2}{*}{$\begin{array}{l}\text { Sample Mean } \\
\text { (M) }\end{array}$} & \multirow[t]{2}{*}{ STDEV } & \multirow{2}{*}{$\begin{array}{l}\text { T Statistics } \\
\text { (|O/STDEV|) }\end{array}$} & \multicolumn{2}{|c|}{ Confidence Interval } \\
\hline & & & & & $2.5 \%$ & $97.5 \%$ \\
\hline CA1 & 0.780 & 0.779 & 0.058 & 13.444 & 0.630 & 0.866 \\
\hline CA2 & 0.739 & 0.738 & 0.062 & 11.945 & 0.588 & 0.833 \\
\hline $\mathrm{CA3}$ & 0.859 & 0.857 & 0.028 & 30.194 & 0.795 & 0.905 \\
\hline CA4 & 0.763 & 0.764 & 0.056 & 13.673 & 0.625 & 0.850 \\
\hline CA5 & 0.802 & 0.800 & 0.069 & 11.591 & 0.623 & 0.898 \\
\hline CA6 & 0.820 & 0.821 & 0.037 & 22.415 & 0.726 & 0.878 \\
\hline МАКТР & 0.867 & 0.864 & 0.040 & 21.690 & 0.758 & 0.919 \\
\hline OPERP & 0.739 & 0.727 & 0.084 & 8.799 & 0.523 & 0.847 \\
\hline CUSAT & 0.835 & 0.838 & 0.039 & 21.412 & 0.727 & 0.895 \\
\hline CRM & 0.663 & 0.659 & 0.068 & 9.691 & 0.500 & 0.770 \\
\hline
\end{tabular}

Notes $1: * \mathrm{t}>1.96$ at $5 \%$ confidence interval in a two-tail test Original Sample $(\mathrm{O})=$ Standardised indicator loadings

\subsubsection{Construct Reliability and Validity}

The current study used three metrics to assess thereliability of both SCMPs and ORGPER Cronbach's alpha (a), Joreskog's compositereliability $\rho c$ and Gold- steins Dillion composite reliability $\rho$ A. According to Hair, et al. (2017), the value ofCronbach's alpha, composite reliability (CR), and rhoA should be higher than 0.7 to establish the construct reliability. However, reliability score $>0.95$ impliesthat the individual items measure the same concept, and are therefore redundant (Manuela, 2019). Further, convergent validity was assessed by the use of theAverage Variance Extracted (AVE) metric. Accordingly, AVE value of 0.5 is citedas the minimum criterion to establish the convergent validity of a construct. Thestandards of Cronbach's alpha, composite reliability (CR), and RhoA, (see Table 2) Minimum above thresholdof 0.7, show sufficient internal consistency for three builds. Additionally, AVEvalues of SCMPs, CA and ORGPER range from 0.561 to 0.665 , indicating that thethree latent variables meet construct validity standards since they imprisonover $50 \%$ of their invisibility indicators.

Table 2

Construct Reliability and Validity

\begin{tabular}{|c|c|c|c|}
\hline & HTMT & $2.5 \%$ & $97.5 \%$ \\
\hline LOGISTIC PERFORMANCE $\rightarrow$ COMPETITVE ADVANTAGE & 0.834 & 0.702 & 0.940 \\
\hline SCM PRACTICES $\rightarrow$ COMPETITVE ADVANTAGE & 0.847 & 0.676 & 0.986 \\
\hline SCM PRACTICES $\rightarrow$ Logistic PERFORMANCE & 0.763 & 0.582 & 0.903 \\
\hline
\end{tabular}

Notes 2: AVE $=$ Average modification extracted, $\boldsymbol{\rho}_{\boldsymbol{r h o}}=$ Dillon-Goldstein, $\boldsymbol{\rho} \mathrm{c}=$ Joreskog's Composite reliability. All metrics should be $\geq 0.7$

\subsubsection{Discriminantvalidity}

The traditional approach for assessing discriminant validityrelies on examining (i) the Fornell-Larcker criterion, and (ii) cross-loadings (Memia, 2018). However, Henseler, Ringle, \& Sarstedt, claims that the two approaches cannotreliably discern the absence of discriminant validity in most researchscenarios and instead, proposed Heterotrait-monotrait (HTMT) ratio ofcorrelations as an alternative (Masdek \& Othman, 2014). Thus, the current study utilized HTMT metric andconfidence intervals to assess if the upper bound of the $95 \%$ confidence intervalof HTMT is lower than 0.9 . Table 3 shows HTMT values ranging from 0.763 to 0.847 , Whichis below the conservative limit of more than 0.85 . In addition, the analysisshows that the C197.s\% value from the bias-revised and quicker (BCa)bootstrapping method includes a more traditional limit value of 0.85 , directingthat lazy variables see discriminatory trial criteria and with each other.

Table 3

HTMT Results

\begin{tabular}{|c|c|c|c|c|}
\hline LATENT VARIABLE & Cronbach's Alpha & $\begin{array}{c}\text { Composite Reliability } \\
\text { Rho_A }\end{array}$ & Composite reliability $(\rho c)$ & $\begin{array}{l}\text { Average Variance } \\
\text { Extracted (AVE) }\end{array}$ \\
\hline $\mathrm{CA}$ & 0.883 & 0.884 & 0.911 & 0.632 \\
\hline ORGPER & 0.751 & 0.777 & 0.856 & 0.665 \\
\hline SCMPs & 0.804 & 0.830 & 0.864 & 0.561 \\
\hline
\end{tabular}

\subsection{Evaluation of Structural Model}

The first step in evaluating structural models is to test for linear. The current study uses various inflation factors (VIF) with decision criteria (Hair, Hult \& Christian, 2017) cut to 3 and below. Below the set limit of VIF value 3 for both external and internal models, the absence of a kalinariati problem in the lazy variable sits. The previous steps in evaluating the structural 
model follow the procedure described by (Hair, Howard \& Nitzl, 2020). In particular, this process determines R2, impact size $/ 2$, and predictability of the model by relevance (Q2) to assess the predictor or interpretive ability, as well as the path coefficient $(\mathrm{P})$ estimate.

\subsubsection{Model Interpretive Strength}

Model interpretive ability is tested considering the associate of adjustment R2 to determine the explanation for the variable dependent on the study. In general, the coordinated R2 value is 0 to 1 , the high value directs a greater interpretive force. According to Joseph F. Hare etc., according to (2017), r2 standards are considered to be $0.75,0.50,0.25$, and below (Hair, Hult \& Christian, 2017). significant, moderate and weak respectively. In addition, Cohen's impact size (f2) is assessed using SCMPs effect size $\left(\mathrm{f}^{2}\right)$ on each of the three dimensions of ORGPER construction. According to Hair, Howard \& Nitzl (2020), $\mathrm{f}^{2}$ values $0.02,0.15$, and 0.35 respectively, direct small, medium or significant effects on the construction of an endogenous. In addition, the predicted relevance of the model is assessed using stone-gauger indicators (Q2). In this way, an blindfolded algorithm with a distance of seven $(\mathrm{D}=7)$ is executed to achieve q2 value. In general, the Q2 value is $0,0.25$, and is priced higher than 0.5 .

Table 4

Model quality Criteria

\begin{tabular}{cccc}
\hline MODEL & R Square & R Square Adjusted & Effect size (f2) \\
\hline SCMPs $\rightarrow$ CA & 0.533 & 0.528 & 1.142 \\
SCMP $\rightarrow$ ORGPER & 0.509 & 0.498 & 0.053 \\
CA $\rightarrow$ ORGPER & & & 0.259 \\
\hline $\begin{array}{l}\text { Notes } 3: \mathrm{R}^{2} \text { values } 0.75=\text { substantial }, 0.50=\text { moderate and }<0.25=\text { weak, } \mathrm{Q}^{2}>0=\text { small, } \mathrm{Q}^{2} 0.25=\text { Medium and } \mathrm{Q}^{2}>0.5 \text { substantial predictive relevance, } \mathrm{f}^{2} \\
>0.02=\text { small, }>0.15=\text { medium, and }>0.35=\text { substantial effect }\end{array}$
\end{tabular}

The results show Adjusted $\mathrm{R}^{2}=0.528$ and 0.498 indicating moderate explanatory power of the model. In other words, SCMPs explain 52.8\%, of the variance of competitive advantage. Additionally, both SCMPs and CA explains $49.8 \%$, of the variance of target variable ORGPER. These results indicate that SCMPs have a substantial effect on CA and a small effect on ORGPER while CA has a medium effect on ORGPER. Furthermore, results from blindfolding show SCMPs $>$ CA $\left(\mathbf{Q}^{2}\right)=\mathbf{0 . 3 2 5}$, SCMPs $>$ ORGPER $\left(\mathrm{Q}^{2}\right)=0.310$, signifying medium predictive relevance. See a summary of these results in Table 4.

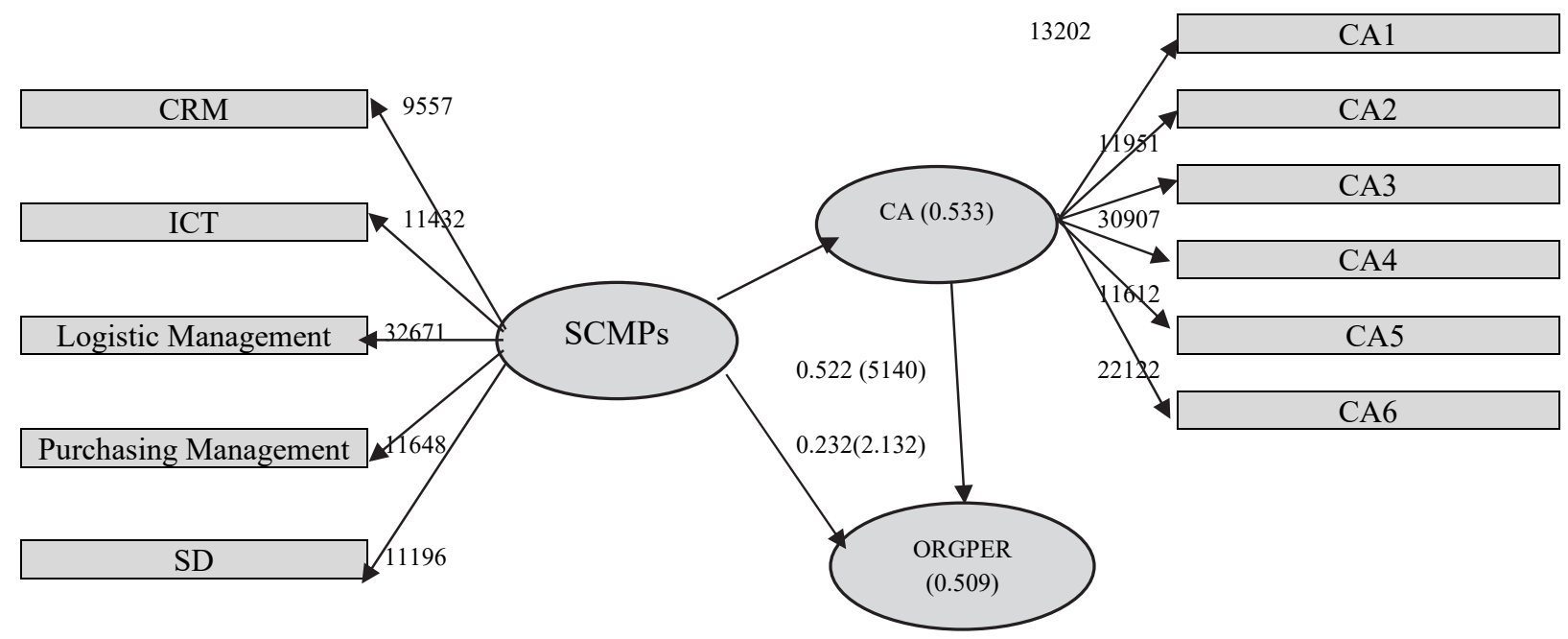

Fig. 3. Structural Modal

The standard path for three structural relationships is shown in Co-efficiency $(\beta)$ (Value outside bracket) figure 3. It is found that the link between SCMP and CA is a positive path coefficient $(\beta=0.730)$ directing that unit growth in SCMP will positively increase SCMP by $73 \%$. In addition, the connection between SCMPs and ORGPER is a positive path partner ( $\beta$ $=0.237$ ) that a unit increase in SCMP will positively increase ORGPER by $23.7 \%$. Furthermore, the link between CA and ORGPER $(\beta=0.522)$ directs that the increase of a unit of theCAwill positively increase the ORGPER by $52.2 \%$.

\subsubsection{Hypothesis testing}

Recently, the study recommended the use of t-value and confidence intervals to test the importance of co-efficiency and guess testing along the way (Rasoolimanesh \& Ali, 2018). According to the Trust Break data and sample size parameters that depend on the variety of parameters, they provide information about the sustainability of approximate companionability by proposing different reasonable population standards. In this way, research is effective in bias-correcting and accelerating 
(BCa) bootstrap in SmartPLS algorithms with 5000 subsamples in two-leg tests at the importance level. Bootstrapping results are displayed on extraction Table 5. The results show that path associate for structural relationships - > ORGPER $(\beta$ $=0.237)$ is statistically significant $(\mathrm{P}<0.05, \mathrm{t}=2.183)$ and the confidence break for approximate path associate is not included zero. This result confirms Estimate 1, which states that high levels of SCM practice are related with height levels of logistic performance. This result is consistent with previous research. For example, a study by Abe, Bempa, and Ousu (2013) found a direct and significant relationship between SCMP and Logistic performance (Nitzl, Salgueiro \& Cepeda-Carrión, 2016). Another study by Babatunde, Gbadian, and Bamidiro, Nigeria has unveiled a positive and significant relationship between SCMP and Logistic performance from select marketers of petroleum products. Furthermore, the results show that path associate for structural relations $\rightarrow \mathrm{CA}(\boldsymbol{\beta}=0.731)$ is statistically significant $(\mathrm{P}<0.05, \mathrm{t}=11.494)$ and the confidence break for approximate road cooperation is not included in zero. This result confirms hypothesis $\mathbf{2}$, which states that higher the level of supply chain management practices is associated with higher levels of competitive advantage. A study by Henseler \& Sarstedt (2013) established a direct relationship between the competitive advantages of SCMP and Food Processing SMEs in Malaysia (Dikshit \& Trivedi, 2012). In addition, Wijetunj \& Ranwala (2018) have exposed a positive relationship between SCM practices and competition scm practices and competitions on medium-sized entrepreneurs in Sri Lanka. In addition, the results for structural relationships do not include $\mathrm{CA} \rightarrow$ ORGPER $(\boldsymbol{\beta}=0.522)$ statistically significant $(\mathrm{P}<0.05$, $\mathrm{t}=5.140$ ) and zero confidence breaks for approximate path associates. This result confirms estimate 3 , which says that high levels of competitive advantage are linked to high levels of ORGPER. (Dikshit \& Trivedi, 2012). A study by, found a positive and statistically important relationship between CA and ORGPER on the cement industry in Indonesia.

Table 5

\begin{tabular}{|c|c|c|c|c|c|c|c|}
\hline \multirow[t]{2}{*}{ PATH } & \multirow{2}{*}{$\begin{array}{c}\text { Original } \\
\text { Sample }(\mathrm{O})\end{array}$} & \multirow{2}{*}{$\begin{array}{c}\text { Sample } \\
\text { Mean } \\
\text { (M) }\end{array}$} & \multirow{2}{*}{$\begin{array}{c}\text { Standard } \\
\text { Deviation } \\
\text { (STDEV) }\end{array}$} & \multirow{2}{*}{$\begin{array}{c}\text { T Statistics } \\
(|\mathrm{O} / \mathrm{STDEV}|)\end{array}$} & \multirow[t]{2}{*}{ P Values } & \multicolumn{2}{|c|}{ Confidence intervals } \\
\hline & & & & & & $2.5 \%$ & $97.5 \%$ \\
\hline $\mathrm{CA} \rightarrow$ ORGPER & $0.522 *$ & 0.534 & 0.102 & 5.118 & 0.000 & 0.282 & 0.700 \\
\hline $\mathrm{SCMPs} \rightarrow \mathrm{CA}$ & $0.730 *$ & 0.736 & 0.062 & 11.786 & 0.000 & 0.586 & 0.833 \\
\hline SCMPS $\rightarrow$ ORGPER & $0.237 *$ & 0.229 & 0.110 & 2.148 & 0.032 & 0.021 & 0.456 \\
\hline
\end{tabular}

Notes 4: * Significance t- statistic $>1.96$ and $\mathrm{P}<0.05$ at $5 \%$ confidence level two-tail test

\subsubsection{Mediation analysis}

Further, the study sought to test the mediation effect of competitive advantage to have a better understanding of the role of SCMPs in explaining the variance of ORGPER in the model. To that effect, the procedure outlined for testing mediation effects in PLS-SEM was followed. The first step involved determining the significance of indirect effects and their magnitude, which was accomplished using the bootstrapping technique. According to Carrion, Nitzl \& Roldan (2015), having a significant indirect effect is the key to determining the type of mediation effect and its magnitude (Carrion, Nitzl $\&$ Roldan, 2017). Subsequently, bootstrap analysis (see Table 6) shows that both the direct $(\boldsymbol{\beta}=\mathbf{0 . 3 8 1})$ and indirect $(\boldsymbol{\beta}=$ 0.381) effects are statistically significant, which is a clear manifestation of partial mediation. These results confirm hypothesis 3, stating that competitive advantage mediates the relationship between SCM practices and logistic performance. The results agree with previous studies, which revealed that SCMPs first generates a competitive advantage, which in turn leads to enhanced logistic performance. A study by Brulhart \& Moncef, (2015) revealed a partial mediation effect between SCM practices and logistic performance. Also, Dikshit ands Trivedi (2012) found a partial mediation effect of CA on the relationship between SCM and company performance on public manufacturing industry in Jabodetabek.

Table 6

Significance of Indirect effect

\begin{tabular}{cccccc}
\hline RELATIONSHIP & $\begin{array}{c}\text { Total } \\
\text { Effect }\end{array}$ & $\begin{array}{c}\text { Direct } \\
\text { effect }\end{array}$ & Indirect effect & T Statistics $(|\mathrm{O} / \mathrm{STDEV}|)$ & P Values \\
\hline SCMPs $\rightarrow$ ORGPER & $0.618^{*}$ & $0.237^{*}$ & $0.381^{*}$ & 4.545 & 0.000 \\
SCMPs $\rightarrow$ CA & $0.730^{*}$ & $0.730^{*}$ & 11.494 & 0.000 & Supported \\
CA $\rightarrow$ ORGPER & $0.522^{*}$ & $0.522^{*}$ & 5.140 & 0.000 & Supported \\
\hline
\end{tabular}

Notes 5: * Significance at t-statistic $>1.96$ and $\mathrm{P}<0.05$ at $5 \%$ confidence level two-tail test:

Further, the variance accounted for (VAF) was calculated to assess the magnitude of the mediation effect using the formula below.

$$
V A F=\frac{\text { indirect effect }}{\text { total } \text { effect }}=\frac{0.730 * 0.522}{0.618}=0.616
$$

The indirect effect equals the product of both the link between SCMPs $>$ CA (0.730) and CA $>$ ORGPER (0.522). On the other hand, the total effect equals the sum of the direct link between SCMPs >ORGPER (0.237) and the indirect effect. According to Hair, Hult \& Christian (2017), partial mediation is established when VAF exceeds the 0.2 threshold level, and that full mediation is demonstrated when it exceeds 0.8 . Results show that $61.6 \%$ of the total effect is due to mediation effects. Thus, the relationship between SCMP and logistic performance is significantly mediated by competitive advantage. 


\subsubsection{Importance Performance Map Analysis (IPMA)}

A post-hoc analysis was executed using the importance- performance matrix analysis (IPMA) by setting logistic performance as the target construct (Brulhart \& Moncef, 2015). The method allows managers to improve management strategies since it indicates the main factors that require an immediate response or improvement (Rakhman, Surachman \& Sumiati, 2016). The importance scores are the total effects of the outcome variable in the structural equation model. Further, performance values or index are derived by rescaling the latent variables score ranging from 0 to 100 . The higher the factor yield, the closer the factor is to 100 , and all total effects should be higher than 0.10 and significant at $p<0.05$ (Rasoolimanesh \& Ali, 2018). Thus, the preference will be on improving the performance of those constructs that indicates importance about their explanation of a target construct, even though at the same time having a relatively low Performance (Sarstedt \& Cheah, 2019; Shmueli, et al. 2019; Spina, et al., 2015; Storer, et al., 2014). Fig. 4 presents the total effects (importance) on the $\mathrm{x}$-axis and mean values (performance) on the $\mathrm{y}$-axis used for the importance-performance matrix analysis. From the results, logistics management has a relatively high total effect on ORGPER followed by ICT, SD, PM and CRM in that order. Specifically, LM has a positive total effect $=0.199$ (importance) on the ORGPER, indication that a 1-unit increase LM will increase the performance of ORGPER by 0.199 ceteris paribus. However, LM has the lowest performance index compared to the other indicators of SCM practices.

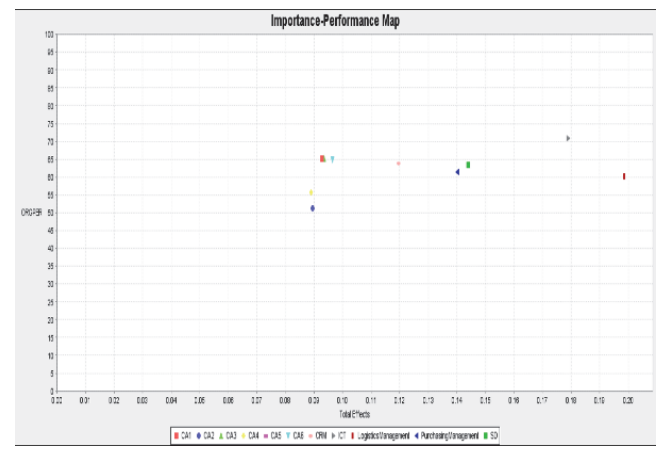

Fig. 4. Importance Performance Matrix Analysis for target Variable ORGPER

\section{Discussions and Conclusion}

The paper is intended to analyze the direct and indirect impact of the randpi, which is analyzed as a mediating variable through competitive advantage. Road analysis results state that all road partners are positive. Four estimates are accepted at $5 \%$ importance level. In particular, the results show that both SCMP and CA have a positive and statistically significant impact on ORGPAR. However, there is a more direct impact on CA(p=0.730) than the SCMP ORGPper $(p=0.237)$. Logically, the relatively low impact of SCMP is due to other factors that may affect Logistic performance, which were outside the scope of this study. Despite the relatively low direct impact of SCMP on ORGPER, SCMP (0.618) (0.203+ $(0.730 * 0.522)=0.618)$ is the critical role of SCMP. Logistic Management among the five external drivers had the strongest impact on ORGRGR (0.199), followed by ICT (0.179), SD (0.144), PM (0.140) and CRM (0.120). The results uncover complex areas where management and policy-making can focus on increasing competitive advantages and improving Logistic performance in the dairy industry. Therefore, it is recommended that managers pay special attention to logistics activities which positively affect both competitive advantages and Logistic performance in the dairy industry. Similarly, managers should focus on logistics activities that try to make milk collection hopeful through systems such as milk runs, bulking in strategic positions and setting cooling facilities. At the same time, logistics issues have to be addressed beyond the objectives of policy intervention initiatives by both national and local governments. In particular, local and national governments should link up with road infrastructure, national grids and alternative sources of cheap fuel and tax systems to encourage investment in cold supply chain equipment.

\subsection{Conclusions}

The study sought to establish structural ties between SCMP, competitive advantage and ORGPER using Kenya's dairy supply chain. The results ensure that SCM plays a very significant part in ensuring modest benefit and improving overall logistic performance of the dairy industry. The SCMPs effect on ORGPER can be either directly or indirectly through competitive advantages. Therefore, the SCMP growth could provide a high level of competitive advantage and Logistic performance in Kenya's dairy industry. The current research was not without limitations. The focus of the current research was on SCMP as the main decisive factor in Logistic performance. However, ORGPER is influenced by many elements; So focusing on one subject can be unfinished. Therefore, future research should consider the impact of modernization of elements such as operational enforcement, capital, technology, and management capacity. In addition, the current research is the model in construction because of the relationship taking on recurring relationships. However, the relationship between research construction can be complex and not always direct since increased competitive advantage, and enhanced Logistic performance can improve the level of SCM practice. Therefore, future research should consider non-recurring models in SCMP, CA, and logistic performance. 


\section{References}

Abbey, W. M., Owusu-Bempah, G., \& Owusu, I. (2013). Assessing the Relationship between Supply Chain Management and Organisational Performance in the Filtered Water Industry in Ghana. International Journal of Business Management \& Research (IJBMR), 3(5), 97-108.

Ali, F., Rasoolimanesh, S. M., Sarstedt, M., Ringle, C. M., \& Ryu, K. (2018). An assessment of the use of partial least squares structural equation modeling (PLS-SEM) in hospitality research. International Journal of Contemporary Hospitality Management, 30(1), 514-538.

Anatan, L. (2014). Factors Influencing Supply Chain Competitive Advantage and Performance. International Journal of Business and Information, 9(3), 311.

Apopa, V. A. (2018). Influence of Supply Chain Management Practices on Performance of Government Ministries in Kenya (Doctoral dissertation, JKUAT-COHRED). http://hdl.handle.net/123456789/4546

Arham, A. F. (2014). The relationship between leadership behaviour, entrepreneurial orientation and organisational performance in malaysian small and medium enterprises (Doctoral dissertation, Royal Melbourne Institute of Technology).

Babatunde, B. O., Gbadeyan, R. A., \& Bamiduro, J. A. (2015). Supply chain management practices and market performance: Evidence from selected major marketers of petroleum products in Nigeria. Pacific Journal of Science and Technology, 7(1), 129-139.

Banerjee, M., \& Mishra, M. (2017). Retail supply chain management practices in India: A business intelligence perspective. Journal of Retailing and Consumer Services, 34, 248-259.

Barasa, P. W. (2017). Contributions of Supply Chain Management Practices on the Performance of Steel Manufacturing Companies in Kenya (Doctoral dissertation, COHRED, JKUAT).

Carrión, G. C., Nitzl, C., \& Roldán, J. L. (2017). Mediation analyses in partial least squares structural equation modeling: Guidelines and empirical examples. In Partial least squares path modeling (pp. 173-195). Springer, Cham.

CHEGE, P. W. (2017). Influence of Internal Business Value Chain Practices On The Supply Chain Performance Of Large Manufacturing Firms In Kenya (Doctoral dissertation, COHRED, JKUAT).

Diaconu, D. M., \& Alpopi, C. (2014). Strengths and weaknesses of current Supply Chain Management and initiatives for the future. In Proceedings of the 8th International Management Conference" Management Challenges For Sustainable Development", November 6th-7th, Bucharest, Romania.

Odendaal, H. J. (1981). Variable Decelerations of the Fetal Heart Rate During Antenatal Monitoring. South African medical journal= Suid-Afrikaanse tydskrif vir geneeskunde, 59(27), 979-981.

Dikshit, P. S. K., \& Trivedi, D. S. (2012). Impact of supply chain management practices on competitive edge and organisational performance: study of cement industry. Paradigm, 16(2), 67-81.

Dries, L., Gorton, M., Urutyan, V., \& White, J. (2014). Supply chain relationships, supplier support programmes and stimulating investment: evidence from the Armenian dairy sector. Supply Chain Management: An International Journal, 19(1), 98-107.

Fornell, C., \& Larcker, D. F. (1981). Evaluating structural equation models with unobservable variables and measurement error. Journal of marketing research, 18(1), 39-50.

Franke, G., \& Sarstedt, M. (2019). Heuristics versus statistics in discriminant validity testing: a comparison of four procedures. Internet Research: Electronic Networking Applications and Policy, 29(3), 430-447.

Garson, G. D. (2016). Partial least squares. Regression and structural equation models. G. David Garson and Statistical Associates Publishing, 11-20.

Prajapati, H., Kant, R., \& Gorane, S. (2018). Impact study of supply chain practices on organisational performance for Indian chemical industries. International Journal of Logistics Systems and Management, 31(1), 20-38.

Hair Jr, J. F., Howard, M. C., \& Nitzl, C. (2020). Assessing measurement model quality in PLS-SEM using confirmatory composite analysis. Journal of Business Research, 109, 101-110.

Hair, J. F., Hult, G. T. M., \& Christian, M. (2017). ringle, and Marko Sarstedt. A Primer on Partial Least Squares Structural Equation Modeling (PLS-SEM), 19(2), 139-152

Hair, J. F., Risher, J. J., Sarstedt, M., \& Ringle, C. M. (2019). When to use and how to report the results of PLSSEM. European Business Review, 31(1), 2-24.

Sarstedt, M., Hopkins, L., \& Kuppelwieser, V. G. (2014). Partial least squares structural equation modeling (PLS-SEM): An emerging tool in business research. European Business Review, 26(2), 106-121.

Henseler, J., Dijkstra, T. K., Sarstedt, M., \& Ringle, C. M. Diamantopoulos, a., Straub, DW, Ketchen, DJ, et al.(2014), “Common Beliefs and Reality About PLS: Comments on Ronkko and Evermann (2013)". Organizational Research Methods, 17(2), 182-209.

Henseler, J., Ringle, C. M., \& Sarstedt, M. (2015). A new criterion for assessing discriminant validity in variance-based structural equation modeling. Journal of the academy of marketing science, 43(1), 115-135.

Henseler, J., \& Sarstedt, M. (2013). Goodness-of-fit indices for partial least squares path modeling. Computational statistics, 28(2), 565-580.

Hwang, H., Sarstedt, M., Cheah, J. H., \& Ringle, C. M. (2020). A concept analysis of methodological research on compositebased structural equation modeling: bridging PLSPM and GSCA. Behaviormetrika, 47(1), 219-241.

Johnson, G. I., \& Hofman, P. J. (2004). Agriproduct supply-chain management in developing countries. Proceedings of a workshop held in Bali, Indonesia, 19-22 August 2003 (Vol. 119). ACIAR. 
Hair Jr, J. F., Sarstedt, M., Ringle, C. M., \& Gudergan, S. P. (2017). Advanced Issues in Partial Least Squares Structural Equation Modeling. SAGE Publications.

Koh, L. C., Demirbag, M., Bayraktar, E., Tatoglu, E., \& Zaim, S. (2007). The impact of supply chain management practices on performance of SMEs. Industrial Management and Data Systems, 107(1), 103-124.

Kumar, R. (2020). Organizational performance through dairy supply chain management practices: A winning approach. In Supply Chain and Logistics Management: Concepts, Methodologies, Tools, and Applications (pp. 1519-1531). IGI Global.

Manuela, P.G.C. (2019). The Impact of Supply Chain Management Processes On Competitive Advantage and Logistic Performance. The Strategic Journal of Business and Change Management, 6(2), pp 2458-2470.

Martínez-Navalón, J. G., Gelashvili, V., \& Debasa, F. (2019). The impact of restaurant social media on environmental sustainability: An empirical study. Sustainability, 11(21), 6105.

Memia, F. K. (2018). Influence Of Contemporary Supply Chain Practices On Performance Of Large Manufacturing Firms In Kenya (Doctoral dissertation, JKUAT-COHRED). http://hdl.handle.net/123456789/4812

Masdek, N. R. N. M., \& Othman, M. F. (2014). Supply chain management practices as a source of competitive advantage for food processing SMEs in Peninsular Malaysia. Economic and Technology Management Review, 9a, 19-28.

Nitzl, C., Roldán Salgueiro, J. L., \& Cepeda-Carrión, G. (2016). Mediation analysis in partial least squares path modeling: Helping researchers discuss more sophisticated models. Industrial Management and Data Systems, 116 (9), $1849-1864$.

Brulhart, F., \& Moncef, B. (2015). Causal linkages between supply chain management practices and performance. Journal of Manufacturing Technology Management, 26(5), 678-702.

Rakhman, A., Surachman, R.,\& Sumiati, M. (2016). The Effect Of Supply Chain Integration, Supply Chain Flexibility And Supply Chain Management Practices On Competitive Advantage And Their Performance Moderated By Environment Uncertainty In Manufacturing Industry Go Public In Jabodetabek. IJABER, 14(3), 2015-2042.

Rasoolimanesh, S. M., \& Ali, F. (2018). Guest editorial. Journal of Hospitality and Tourism Technology, 9(3), 238-248.

Sarstedt, M., \& Cheah, J. H. (2019). Partial least squares structural equation modeling using SmartPLS: a software review. Journal of Marketing Analytics, 7(3), 196-202.

Shmueli, G., Sarstedt, M., Hair, J. F., Cheah, J. H., Ting, H., Vaithilingam, S., \& Ringle, C. M. (2019). Predictive model assessment in PLS-SEM: guidelines for using PLSpredict. European Journal of Marketing, 53(11), 2322-2347.

Spina, D., Di Serio, L. C., Brito, L. A., \& Duarte, A. L. D. C. M. (2015). The influence of supply chain management practices in the enterprise performance. American Journal of Management, 15(2), 54.

Storer, M., Hyland, P., Ferrer, M., Santa, R., \& Griffiths, A. (2014). Strategic supply chain management factors influencing agribusiness innovation utilization. Management, 25(3), 487-521.

Lorentz, H., Shi, Y., Hilmola, O. P., Srai, J. S., Sundram, V. P. K., Ibrahim, A. R., \& Govindaraju, V. C. (2011). Supply chain management practices in the electronics industry in Malaysia.Benchmarking: An International Journal, $18(6), 834-855$.

Sundram, V. P. K., Ibrahim, A. R., \& Govindaraju, V. G. R. (2011). Supply chain management practices in the electronics industry in Malaysia: Consequences for supply chain performance. Benchmarking: An International Journal, 18(6), 834-855

Tailab, M. M. K. (2020). Using Importance-Performance Matrix Analysis to Evaluate the Financial Performance of American Banks During the Financial Crisis. SAGE Open, 10(1), 2158244020902079.

Tatoglu, E., Bayraktar, E., Golgeci, I., Koh, S. L., Demirbag, M., \& Zaim, S. (2016). How do supply chain management and information systems practices influence operational performance? Evidence from emerging country SMEs. International Journal of Logistics Research and Applications, 19(3), 181-199.

Tsolakis, N. K., Keramydas, C. A., Toka, A. K., Aidonis, D. A., \& Iakovou, E. T. (2014). Agrifood supply chain management: A comprehensive hierarchical decision-making framework and a critical taxonomy. Biosystems Engineering, 120, 47-64.

Maina, C., Njehia, B. K., \& Eric, B. K. (2020). SOURCES OF COMPETITIVE ADVANTAGE IN THE DAIRY INDUSTRY: SUPPLY CHAIN MANAGEMENT PRACTICES. International Journal of Supply Chain Management, 5(1), 54-72.

Wijetunge W.A.D.S. (2016). The Role of Supply Chain Management Practices in Achieving Logistic Performance Through Competitive Advantage in Sri Lankan SMES. In Proceedings of 54th ISERD International Conference Singapore,6-13.

Wong, K. K. K. (2019). Mastering partial least squares structural equation modeling (PLS-Sem) with Smartpls in 38 Hours. IUniverse.

Wong, W. P., \& Wong, K. Y. (2011). Supply chain management, knowledge management capability, and their linkages towards firm performance. Business Process Management Journal, 17(6), 940-964.

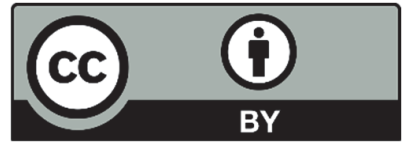

(C) 2021 by the authors; licensee Growing Science, Canada. This is an open access article distributed under the terms and conditions of the Creative Commons Attribution (CC-BY) license (http://creativecommons.org/licenses/by/4.0/). 